\title{
Estimation of Additive and Non-Additive Genetic Variances of Body Weight, Egg Weight and Egg Production for Quails (Coturnix coturnix japonica) with an Animal Model Analysis
}

\author{
Dedicated to Professor Dr. Gerhard Seeland on the occasion of his $65^{\text {th }}$ birthday
}

\begin{abstract}
This study estimates the additive and non-additive variances for egg production and body weight traits of two lines of quails from a long-term selection with the help of the REML method. For the body weight of 42-day-old females (BW42f) and males (BW42m), a total of 7,934 records for line 1 and 7,214 records for line 2 from 21 generations were used in our analyses. Additionally, 1,717 records of females from line 1 and 1,671 records of females from line 2 contained information on their egg production at an age of 42 to 200 days (EN200), on the average egg weight for the first 11 weeks of their laying season (EW1), on the average egg weight from weeks 12 to 23 (EW2), and on their body weight at an age of 200 days (BW200f). A multivariate additive animal model and one-trait dominance models, which include the inbreeding coefficients as covariates, were fitted to the data. The estimates of the heritability gained from our dominance models were smaller than those from the additive model. For line 1, the heritability values decreased for EN200 from 0.35 to 0.32, for EW1 from 0.66 to 0.56 , for BW200f from 0.42 to 0.38 , and for BW200m from 0.51 to 0.49 , respectively. For the first line, the respective ratio $\left(\mathrm{d}^{2}\right)$ of the dominance variance to the phenotypic variance for EN200, EW1, BW200f and BW200m was $0.08,0.22,0.09$ and 0.21 , and the values for the second line were $0.12,0.06,0.001$ and 0.23 .
\end{abstract}

Key Words: dominance, Japanese quails, variance components

\section{Zusammenfassung}

Titel der Arbeit: Schätzung von additiver und nicht-additiver genetischer Varianz für Körpergewicht, Eigewicht und Eiproduktion der Wachtel (Coturnix coturnix japonica) mit Tiermodellen

In dieser Studie werden additive und nicht-additive Varianzen für die Eiproduktion und das Körpergewicht an zwei Selektionslinien der Wachtel mit Hilfe der REML-Methode geschätzt. Für das Körpergewicht der weiblichen (BW42f) und männlichen (BW42m) Tiere am 42. Lebenstag standen in Linie 1 bzw. 2 insgesamt 7934 bzw. 7214 Datensätze aus 21 Generationen für die Auswertungen zur Verfügung. Zusätzlich waren für die Eiproduktion zwischen Lebenstag 42 und 200 (EN200), für das mittlere Eigewicht der ersten 11 Wochen der Legeperiode (EW1), für das mittlere Eigewicht innerhalb Woche 12 und 23 (EW2) sowie für das Körpergewicht am 200. Lebenstag (BW200f) in Linie 1 bzw. 2 Leistungen von 1717 bzw. 1671 weiblichen Tieren vorhanden. Zur genetischen Auswertung wurden ein additives Mehrmerkmalsmodell und Einmerkmals-Dominanzmodelle, welche die Inzuchtkoeffizienten als Kovariable enthielten, angepasst. Die Schätzungen der Heritabilität aus den Dominanzmodellen waren geringer als jene geschätzt mit dem additiven Modell. Innerhalb Linie 1 verringerten sich die Schätzwerte für EN200 von 0.35 auf 0.32 , für EW1 von 0.66 auf 0.56 , für EW2 von 0.42 auf 0.38 , für BW200f von 0.42 auf 0.38 und für BW200m von 0.51 auf 0.49 . In Linie 1 wurden für das Verhältnis $\left(\mathrm{d}^{2}\right)$ der Dominanzvarianz zur phänotypischen Varianz für die Merkmale EN200, EW1, BW200f und BW200m Werte von 0.08, 0.22, 0.09 und 0.21 geschätzt während sich für Linie 2 Schätzungen von 0.12, 0.06, 0.001 und 0.23 ergaben.

Schlüsselwörter: Dominanz, Japanische Wachtel, Varianzkomponenten 


\section{Introduction}

Non-additive genetic variation (dominance and epistasy) is an important source of heterosis for traits associated with growth and reproduction in crosses between animals from different populations and lines. Positive heterosis in crosses between divergent selected lines of Japanese quails has been observed not only for egg production but also for body weight and egg weight (MORITSU et al., 1997). Non-additive variation is mainly caused by dominance. There are several reasons why the dominance variance needs to be estimated; these include an unbiased estimation of heritability in a narrow sense, a more precise prediction of additive effects, and the usage of dominance effects through a crossbreeding or special mating strategy. Dominance influences all genetic parameters related to crossbreeding (WEI et al., 1991a, b; RÖHE et al., 2000). Based on HOESCHELE and VanRADEN's algorithm (1991) for the direct generation of the inverse of the dominance relationship matrix, the estimation of dominance variance with REML methodology is now possible for large populations. The estimation of dominance variance has already been done for chickens, dairy cattle, beef cattle and swines (see WEI and VAN der WERF, 1993; MISZTAL et al., 1998). Some research results indicate that poultry egg production is influenced by dominance (FAIRFULL and GOWE, 1986). However, no such estimations have been reported yet for quails (Coturnix coturnix japonica).

The objective of this study is to estimate additive and dominance variances for egg production, egg weight and body weight of two lines of quails by using an animal model analysis.

\section{Materials}

From a base population of Japanese quails, we created two selection lines. The selection criterion for the first line was high body weight and small egg weight over 21 generations, while the criterion for the second line was high egg weight only. For each generation, $50 \%$ of the pairs were selected. For line 1 , the selection was mainly based on an index that included the body weight of females at an age of 42 days (BW42f), the average egg weight for the first 11 weeks of the laying season (EW1), and the average egg weight from week 12 to week 23 (EW2). For line 2, the selection process was only based on the average of EW1 and EW2. The selected animals were mated and full and half-sib mating was avoided. From each selected parent pair, more than one female and male was generated.

From the first to the tenth generation, the lines consisted of 110 pairs (single paired mating), and for generations 11 to 20 , the number of pairs was 80 . The quails were kept in battery cages with three floors.

Table 1

Population structure of lines 1 and 2 (for all hens with an egg production of more than 30 eggs between an age of 42 to 200 days) (Populationsstruktur der beiden Linien)

\begin{tabular}{cccccccccc}
\hline Line & $\begin{array}{c}\text { Number of } \\
\text { pairs }\end{array}$ & \multicolumn{4}{c}{ Number of pairs with offspring (between 1 to 6) in \% } & \multicolumn{2}{c}{ Number of } \\
& pairs & $\mathbf{1}$ & $\mathbf{2}$ & $\mathbf{3}$ & $\mathbf{4}$ & $\mathbf{5}$ & $\mathbf{6}$ & records \\
\hline 1 & 944 & 38.0 & 46.2 & 12.5 & 2.5 & 0.6 & 0.1 & 1717 \\
2 & 900 & 37.1 & 44.9 & 14.1 & 3.2 & 0.4 & 0.2 & 1671 \\
\hline
\end{tabular}

We observed the following traits: the body weight of females (BW42f) and males (BW42m) at an age of 42 days, EN200, EW1, EW2, and the body weight of females (BW200f) and males (BW200m) at an age of 200 days. Table 1 shows the full-sib 
structure of the parent pairs kept in cages. The number of pairs with offspring ranges from 1 to 6 in our lines. In total, 38.0\% of the females in line 1 and $37.1 \%$ of the females in line 2 do not have any full-sisters with records in other cages. Since we included an average of two females per parent pair in our analysis, the estimation of the dominance variance is possible. Table 2 shows the descriptive statistics for all of our eight investigated traits. For the traits egg weight and egg number, table 2 contains only records for all those females that reached the end of the analysis period. The body weight of females and males at an age of 42 days and of 200 days was considered a different trait for the respective cases.

Table 2

Number of records $(\mathrm{N})$, mean values $(\bar{X})$, standard deviation (std), minimum and maximum value of traits measured for females and of body weight measured for females (f) and males (m) at the beginning and at the end of the laying period (Beschreibende Statistik)

\begin{tabular}{lcccccccccc}
\hline Trait & $\mathbf{N}$ & $\bar{x}$ & $\begin{array}{c}\text { Line 1 } \\
\text { std }\end{array}$ & $\mathbf{m i n}$ & $\mathbf{m a x}$ & $\mathbf{N}$ & $\bar{x}$ & $\begin{array}{c}\text { Line 2 } \\
\text { std }\end{array}$ & $\mathbf{m i n}$ & $\mathbf{m a x}$ \\
\hline EN200 & 1717 & 126.39 & 22.930 & 31.0 & 160.0 & 1671 & 120.20 & 25.660 & 31.0 & 159.0 \\
EW1 & 1727 & 10.27 & 0.811 & 7.6 & 13.5 & 1722 & 11.45 & 0.935 & 6.1 & 14.7 \\
EW2 & 1695 & 11.25 & 0.959 & 8.2 & 14.8 & 1654 & 12.56 & 1.170 & 8.3 & 16.7 \\
BW42f & 4054 & 162.93 & 22.909 & 75.7 & 235.0 & 3611 & 158.61 & 18.270 & 91.7 & 214.0 \\
BW200f & 1645 & 188.02 & 22.631 & 85.0 & 275.0 & 1598 & 188.62 & 20.297 & 99.0 & 283.0 \\
BW42m & 3880 & 138.36 & 17.595 & 86.6 & 206.0 & 3603 & 135.92 & 13.390 & 71.0 & 215.0 \\
BW200m & 1769 & 171.36 & 23.387 & 100.0 & 259.0 & 1613 & 162.07 & 17.086 & 90.0 & 219.0 \\
\hline
\end{tabular}

3. Models and Methods

The additive genetic parameters of all eight traits were estimated simultaneously, based on the following animal model for an individual record:

$$
y_{i j}=x_{i j}^{\prime} \beta_{j}+a_{i j}+e_{i j}
$$

Here, $y_{i j}$ is the record (trait) $j$ of animal $i ; \beta_{j}$ represents the vector of fixed effects with $x_{i j}$ relating the record on animal $i$ to this vector; $a_{i j}$ is the additive genetic; and $e_{i j}$ is the environmental effect of animal $i$. For the traits observed in cages, vector $\beta_{j}$ contains the block (combined) effect of generation, floor and battery. On the other hand, vector $\beta_{j}$ includes only the environmental effect of a generation for the body weight at an age of 42 days. The matrix representation of model (1) is:

$$
y=X \beta+Z a+e
$$

In this formula, $\beta$ is the vector of fixed effects (defined in model (1)), $a$ is the vector of additive genetic animal effects, $e$ is the vector of residual effects, and $X$ and $Z$ are matrices that relate records to their respective effects. The variance-covariance matrix associated with model (2) is given by:

$$
\operatorname{Var}\left(\begin{array}{l}
a \\
e
\end{array}\right)=\left(\begin{array}{cc}
A \otimes G_{a} & 0 \\
0 & I \otimes R_{e}
\end{array}\right) \text {, with } \otimes \text { as indication of the direct (Kronecker) product. }
$$

In (3), $A$ is the additive genetic relationship matrix, $G_{a}$ is the additive genetic and $R_{e}$ is the environmental variance-covariance matrix of the traits described in Table 2. If two traits cannot be observed simultaneously for the same animal, the corresponding residuals were assumed to be without correlation. 
The dominance variances were estimated by using one-trait models for all seven traits. Since the inbreeding cannot be ignored in our data analysis, the following dominance model was used:

$$
y=X \beta+Z a+Z W f+Z b \Delta+e
$$

Here, $\Delta$ represents the coefficient of inbreeding depression, $b$ is the vector of inbreeding coefficients, and $W$ is the incidence matrix in relation to the vector $f$ of parental dominance effects. The variance-covariance matrices of the random effects in model (4) are:

$$
\operatorname{Var}(a)=A \cdot \sigma_{a}^{2} ; \quad \operatorname{Var}(f)=F \cdot \sigma_{f}^{2}=F \cdot 0.25 \cdot \sigma_{d}^{2} ; \quad \text { and } \quad \operatorname{Var}(e)=I \cdot \sigma_{e}^{2} .
$$

$F$ is the parental-dominance relationship matrix, and $\sigma_{a}^{2}, \sigma_{f}^{2}, \sigma_{d}^{2}$ and $\sigma_{e}^{2}$ are the additive, the parental-dominance, the dominance, and the residual variances, respectively (HÖSCHELE and VAN RADEN, 1991). The estimated variances and covariances in models (2) and (4) were obtained by using the REML-method of the VCE5.0 program (KOVAC et al., 2002).

Table 3

Additive genetic variance ( $\left.\sigma_{a}^{2}\right)$, environmental variance $\left(\sigma_{e}^{2}\right)$ and heritability $\left(\mathrm{h}^{2}\right)$ for lines 1 and 2 , estimated with a multi-trait additive model (Additive Varianz, Umweltvarianz und Heritabilität geschätzt mit einem additiven Mehrmerkmalsmodell)

\begin{tabular}{lcccccc}
\hline & \multicolumn{3}{c}{ Line 1 } & \multicolumn{3}{c}{ Line 2 } \\
Trait & $\sigma_{a}^{2}$ & $\sigma_{e}^{2}$ & $h^{2} \pm s e$ & $\sigma_{a}^{2}$ & $\sigma_{e}^{2}$ & $h^{2} \pm s e$ \\
\hline EN200 & 179.8 & 340.8 & $0.35 \pm 0.03$ & 127.1 & 492.2 & $0.21 \pm 0.03$ \\
EW1 & 0.416 & 0.218 & $0.66 \pm 0.03$ & 0.422 & 0.312 & $0.58 \pm 0.02$ \\
EW2 & 0.466 & 0.414 & $0.53 \pm 0.03$ & 0.430 & 0.616 & $0.41 \pm 0.03$ \\
BW42f & 112.5 & 129.6 & $0.47 \pm 0.02$ & 120.9 & 125.2 & $0.49 \pm 0.02$ \\
BW200f & 131.2 & 183.8 & $0.42 \pm 0.02$ & 148.6 & 199.6 & $0.43 \pm 0.02$ \\
BW42m & 82.90 & 47.3 & $0.64 \pm 0.02$ & 77.80 & 41.76 & $0.65 \pm 0.02$ \\
BW200m & 134.8 & 114.2 & $0.54 \pm 0.02$ & 153.2 & 92.16 & $0.62 \pm 0.03$ \\
\hline
\end{tabular}

4.

Results and Discussion

4.1

Additive Genetic Parameters

The estimated heritability values of the traits are shown in Table 3 . The estimates are similar in both lines. The calculated values are high for EW1, BW42m and BW200m (0.54 to 0.66), medium for BW200f and BW42f (0.42 to 0.49), and relatively low for EN200 (0.21 in line 1 and 0.35 in line 2). We found clear order relations for estimates of the two lines for certain trait complexes. The estimated heritability for the traits EN200, EW1 and EW2 in line 1 is higher than for the same traits in line 2. In general, the heritability values of the four body weight traits are higher for line 2 than for line 1. The estimated heritability of the body weight of the Japanese quail at different ages was reported, for example, by STRONG et al. (1978), TOELLE et al. (1991), BRAH et al. (2001), SAATCI et al. (2003), VALI et al. (2005) and RESENDE et al. (2005). These studies normally used body weights at different ages and often used different methods to estimate the heritability. TOELLE et al. (1991) used the simple full-sib analysis for their heritability estimates of the body weight from sire and dam components and reported values between 0.49 and 0.70. BRAH et al. (2001) analysed 
data from 9 generations of two selected quail lines. They found heritability estimates of 4-week body weight between 0.35 and 0.56 using pooled estimates from sire and dam components. Using animal model analysis and the REML-method, SAATCI et al. (2003) examined the heritability of weights during the hatching period and from week 1 to week 6, and reported values between 0.14 and 0.32. RESENDE et al. (2005) estimated the heritability of body weight based on a multi-trait animal model with additive genetic and maternal effects implementing Gibbs sampling methodology.

The posterior means for the heritability were $0.33,0.35,0.36,0.43$ and 0.47 for the hatching day and an age of 7 days, of 14 days, of 21 days and of 28 days, respectively. The differences in heritability estimates might be attributed to our method of estimation, strains, environmental effects or a sampling error due to small data sets or sample sizes. For genetic evaluations in the studies of RESENDE et al. (2005), SAATCI et al. (2003) and VALI et al. (2005), records of 650, 1,108 and 3,520 animals were used, respectively.

In order to meet the requirements for the sample size, we used records of animals from 21 generations in our study and analyzed them simultaneously. For the body weight at an age of 42 days, a total of 7,934 records for line 1 and 7,214 records for line 2 were used in our analysis. The lines were under moderate pressure of selection over the generations. Therefore, we used the REML method for our estimation of the variance components. From a statistical point of view, this method can handle selected data and provide unbiased estimations of the genetic parameters of the unselected base population. REML yields unbiased estimators of the variances in the base population under the following ideal conditions: (a) the assumptions of the infinitesimal additive genetic model are valid, (b) there are complete pedigrees back to a base population of non-selected, non-related, and non-inbred animals, (c) and data on all candidates for selection are available (SCHAEFFER, et al., 1998). For a long-term selection, the standard assumptions of the infinitesimal model are no longer valid. Parental selection over 20 generations led to changes of allele frequencies, mainly for traits facing special pressure for selection. Thus, the smaller heritability estimates of EW1 and EW2 in line 1 (0.58 and 0. 41), compared to those from line 2 (0.66 and 0.53), result from the direct selection of egg weight in line 2. In contrast, the selection of high body weight in line 1 decreased the heritability of all body weight traits in this line in comparison to the values from line 2 . The influence of the different selection criteria can be seen in the estimated genetic correlations of the two lines (Table 4). For certain combinations of traits, we found clear order relations between the genetic correlations of the lines. The genetic correlations between egg production and egg weight are negative in line 1 (-0.36 and -0.44) and near zero in line 2 (0.10 and 0.07). On the other hand, the genetic correlations between egg weight and body weight are positive and moderately high.

In lines 1 and 2, they were between 0.45 and 0.59 and between 0.21 and 0.44 , respectively. In general, the values of genetic correlations for the egg weight and the body weight in line 1 are higher than those in line 2. The highest genetic correlations were found between the body weight traits. In lines 1 and 2, the estimates ranged from 0.67 to 0.84 and from 0.56 to 0.85 , respectively. The genetic correlations between the body weight of females and males at an age of 42 days and of 200 days were 0.84 and 0.67 for line 1 and 0.76 and 0.67 for line 2, respectively. By using the corresponding standard errors, we can see that these estimates are significantly different from one. 
Consequently, the body weight of females and males at an age of 42 days should be treated differently in the genetic evaluation.

Table 4

Genetic correlations and their standard error for traits of line 1 (above the diagonal) and line 2 (below the diagonal), estimated with an additive model (Genetische Korrelationen und zugehörige Standardfehler für Linie1 oberhalb und für Linie 2 unterhalb der Diagonalen)

\begin{tabular}{lccccccc}
\hline Trait & EN200 & EW1 & EW2 & BW42f & BW200f & BW42m & BW200m \\
\hline EN200 & $*$ & $-0.36 \pm 0.06$ & $-0.44 \pm 0.07$ & $0.07 \pm 0.04$ & $-0.20 \pm 0.05$ & $0.07 \pm 0.04$ & $0.14 \pm 0.04$ \\
EW1 & $0.10 \pm 0.04$ & $*$ & $0.94 \pm 0.01$ & $0.52 \pm 0.03$ & $0.48 \pm 0.04$ & $0.49 \pm 0.03$ & $0.45 \pm 0.03$ \\
EW2 & $0.07 \pm 0.05$ & $0.95 \pm 0.01$ & $*$ & $0.59 \pm 0.03$ & $0.59 \pm 0.04$ & $0.54 \pm 0.03$ & $0.49 \pm 0.03$ \\
BW42f & $0.39 \pm 0.04$ & $0.21 \pm 0.03$ & $0.30 \pm 0.04$ & $*$ & $0.74 \pm 0.04$ & $0.84 \pm 0.02$ & $0.71 \pm 0.04$ \\
BW200f & $0.10 \pm 0.05$ & $0.29 \pm 0.04$ & $0.37 \pm 0.04$ & $0.70 \pm 0.03$ & $*$ & $0.73 \pm 0.03$ & $0.67 \pm 0.02$ \\
BW42m & $0.12 \pm 0.04$ & $0.28 \pm 0.03$ & $0.35 \pm 0.04$ & $0.76 \pm 0.02$ & $0.71 \pm 0.03$ & $*$ & $0.79 \pm 0.02$ \\
BW200m & $-0.02 \pm 0.04$ & $0.31 \pm 0.03$ & $0.44 \pm 0.04$ & $0.56 \pm 0.03$ & $0.67 \pm 0.04$ & $0.85 \pm 0.02$ & $*$ \\
\hline
\end{tabular}

\subsection{Non-Additive Genetic Parameters}

As expected, the estimated $h^{2}$ values for lines 1 and 2 from dominance models were smaller than those from the additive model. The differences between the $h^{2}$ estimates from additive and dominance models were higher for a larger parental dominance variance (Table 5). For example, in line 1, the estimates of the heritability decreased (0.35 to $0.32,0.66$ to $0.56,0.53$ to 0.44 and 0.47 to 0.33 for EN220, EW1, EW2 and BW42f, respectively). The results were in accordance with reports for the egg production trait for chickens (WEI and VAN der WERF, 1993; MIELENZ et al., 2003). The estimated additive variances and heritability values obtained with the dominance model are lower than those gained with the additive model (Tables 3 and 5). This is due to the extraction of the parental dominance variance from environmental and additive variances, which resulted in a decrease of these two estimates and kept the total variance almost unchanged in the dominance model. Larger parental dominance variance estimates were accompanied by larger differences between $\mathrm{h}^{2}$ estimates from additive and dominance models. According to WEI and VAN der WERF (1993), any resemblance between relatives is partly due to dominance effects. In an additive model, part of the resemblance between related animals due to dominance is contained in the estimated additive effects, resulting in an overestimation of additive variances.

Table 5

Additive genetic variance $\left(\sigma_{a}^{2}\right)$, parental dominance variance $\left(\sigma_{F}^{2}\right)$, heritability $\left(h^{2}\right)$ and dominance ratio $\left(d^{2}\right)$, estimated with one-trait models (Additive Varianz, elterliche Dominanzvarianz, Heritabilität und Dominanzverhältnisse, geschätzt mit Einmerkmalsmodellen)

\begin{tabular}{lcccccccc}
\hline Trait & \multicolumn{3}{c}{ Line 1 } \\
& $\sigma_{a}^{2}$ & $\sigma_{F}^{2}$ & $h^{2} \pm s e$ & $d^{2} \pm s e$ & $\sigma_{a}^{2}$ & $\sigma_{F}^{2}$ & $h^{2} \pm s e$ & $d^{2} \pm s e$ \\
\hline EN200 & 162.3 & 9.341 & $0.32 \pm 0.05$ & $0.07 \pm 0.08$ & 99.06 & 18.59 & $0.16 \pm 0.05$ & $0.12 \pm 0.11$ \\
EW1 & 0.336 & .0325 & $0.56 \pm 0.02$ & $0.22 \pm 0.08$ & 0.394 & .0116 & $0.54 \pm 0.05$ & $0.06 \pm 0.06$ \\
EW2 & 0.359 & .0345 & $0.44 \pm 0.03$ & $0.17 \pm 0.07$ & 0.224 & 0.106 & $0.24 \pm 0.06$ & $0.45 \pm 0.12$ \\
BW42f & 75.35 & 26.67 & $0.33 \pm 0.03$ & $0.46 \pm 0.05$ & 89.53 & 20.94 & $0.38 \pm 0.03$ & $0.35 \pm 0.05$ \\
BW200f & 113.2 & 6.962 & $0.38 \pm 0.03$ & $0.09 \pm 0.04$ & 126.9 & .0491 & $0.38 \pm 0.04$ & $.001 \pm 0.02$ \\
BW42m & 62.48 & 13.61 & $0.50 \pm 0.03$ & $0.44 \pm 0.05$ & 62.25 & 7.953 & $0.55 \pm 0.03$ & $0.28 \pm 0.04$ \\
BW200m & 109.9 & 11.71 & $0.49 \pm 0.04$ & $0.21 \pm 0.08$ & 111.4 & 12.58 & $0.52 \pm 0.04$ & $0.23 \pm 0.08$ \\
\hline
\end{tabular}

For the ratio $\left(\mathrm{d}^{2}\right)$ of the dominance variance to the total variance of trait EN200, we found values of 0.07 and 0.12 for line 1 and line 2, respectively. For the egg weight, 
the estimated $\mathrm{d}^{2}$ values varied from 0.17 to 0.22 in line 1 and from 0.06 to 0.45 in line 2. In comparison to similar studies with chickens, these values are strongly overestimated. The $\mathrm{d}^{2}$ value of 0.45 found for EW1 seems to be less likely. Since the highest standard error was calculated for this estimated value, the small sample size might be one explanation for the partial overestimation of dominance ratios of the egg weight trait. However, positive heterosis was observed in crosses between divergently selected lines of quails both for egg production and egg weight (MORITSU et al., 1997). Thus, it is reasonable to expect the existence of dominance variance for the egg weight as well.

Surprisingly, high estimates of $\mathrm{d}^{2}$ values were obtained for the body weight at an age of 42 days for both lines. The estimates of BW42f and BW42m were above 0.44 in line 1 and above 0.28 in line 2. This may be due to the fact that unknown environmental effects had an influence on the early growth rate of the quails. We have no knowledge of the exact circumstances and if all sibs were raised under the same environmental conditions and exposed to the same pathogens. The parental dominance effects might include uncorrelated full-sib or similar effects for traits measured before the quails were kept in cages (MISZTAL and BESBES, 2000). At an age of 42 days, pairs of quails were put into cages in a controlled environment. Since these quails were randomly distributed across cages, possible common environmental effects for fullsibs were ignored for traits measured at later stages in the life of these quails. A second explanation for the overestimation mentioned above may be the fact that the parental dominance variance includes maternal, common environmental and epistatic variances. Maternal effects for chickens have been shown to be important for their early body weight but not for their egg production (FAIRFULL and GROWE, 1986). And last but not least, a third reason might be the insufficient amount of data. Any estimation of the dominance variance requires much larger data sets than an estimation of the additive variance (MISZTAL et. al., 1995; MIELENZ and SCHÜLER, 2004). Additionally, the high $\mathrm{d}^{2}$ estimates for EW and BW may be due to the change of the allele frequencies caused by the selection of the egg weight over more than 20 generations. For our study, this leads to the conclusion that the dominance model should be used mainly to get a more precise estimation of heritability in a narrow sense. Due to missing information for the period of early growth, the genetic interpretation of the results for the body weight at an age of 42 days is less meaningful.

\section{References}

BRAH, G.S.; CHAUDHARY, M.L.; SANDHU, J.S.:

Direct and correlated responses to selection for 4-week body weight in two lines of Japanese quails. Arch. Tierz., Dummerstorf 44 (2001), 99-108

FAIRFULL, R.W.; GOWE, R.S.:

Use of breed resources for poultry egg and meat production. Proceedings of $3^{\text {rd }}$ World Congr. Gent. Appl. Livest. Prod. 10 (1986), 242-256

HOESCHELE, I.; VAN RADEN, P.M.:

Rapid inversion of dominance relationship matrices for noninbred populations by including sire by dam subclasses effects. J. Dairy Sci. 74 (1991), 557-569

KOVAC, M.; GROENEVELD, E.; GARCIA-CORTES, L.A.:

VCE-5 Package for the estimation of dispersion parameters. Proc. $7^{\text {th }}$ WCGALP, Montpellier (2002)

MIELENZ, N.; KOVAC, M.; GROENEVELD, E.; PREISINGER, R.; SCHMUTZ, M.; SCHÜLER, L.: Genetic Evaluation of egg production traits based on additive and dominance models in laying hens. Arch. Tierz., Dummerstorf 46 (2003), 77-84 
MIELENZ, N.; SCHÜLER, L.:

Stichprobenplanung zur Schätzung der Dominanzvarianz bei hierarchischer Halb- und Vollgeschwisterstruktur. Arch. Tierz., Dummerstorf. 47 (2004), 491-499

MISZTAL, I.; BESBES, B.:

Estimates of parental-dominance and full-sib permanent environment variances in laying hens. Animal Science 71 (2000), 421-426

MISZTAL, I.; VARONA, L.; CULBERTSON, M.; GENGLER, N.; BERTRAND, J.K.; MABRY, J.; LAWLOR, T.J.; VAN TASSELL, C.P.: Studies on the value of incorporating effect of dominance in genetic evaluations of dairy cattle, beef cattle and swine. Proc. $6^{\text {th }}$ WCGALP (1998) Armidale

MORITSU, Y.; NESTOR, K.E; NOBLE, D.O.; ANTHONY, N.B.; BACON, W.L.:

Divergent selection for body weight and yolk precursor in Coturnix coturnix japonica . 12. Heterosis in reciprocal crosses between divergently selected lines. Poultry. Sci. 76 (1997), 437-444

RESENDE, R.O.; MARTINS, E.N. ; GEORG, P.C.et al.: Variance components for body weight in Japanese quails (Coturnix japonica). Rev. Bras. Cienc. Avic. 7 (2005), 23-25

RÖHE; R.; KRIETER, J.; PREISINGER, R.:

Bedeutung der Varianzkomponentenschätzung für die Zucht von landwirtschaftlichen Zuchttieren Eine Übersicht. Arch. Tierz., Dummerstorf. 43 (2000), 523-534

SCHAEFFER, L.R.; SCHENKEL, F.S.; FRIES, L.A.:

Selection bias on animal model evaluation. Proc. 6th World Congr. Genet. Appl. Livest. Prod. 25 (1998), 501-508

STAACI, M.; DEWI, A.P.; AKSOY, A.R.:

Application of REML procedure to estimate the genetic parameters of weekly live weights in one-toone sire and dam pedigree recorded Japanese quails. J. Anim. Breed.Genet. 129 (2003), 23-28

STRONG. C.F; NESTOR, K.E.; BACON, W.L.: Inheritance of egg production, egg weight, body weight and certain plasma constituents in Coturnix. Poultry Sci. 57 (1978), 1-9

TOELLE, V.D.; HAVENSTEIN, G.B.; NESTOR, K.E.; HARVEY, W.R.:

Genetic and phenotypic relationships in Japanese quail. 1. Body weight, carcass and organ measurements. Poult. Sci. 70 (1991), 1679-1688

VALI, N.; EDRISS, M.A.; RAHMANI, H.R.:

Genetic Parameters of Body and Some Carcass Traits in Two Quail Strains. International Journal of Poultry Science 4 (2005), 296-300

WEI, M.; VAN der WERF, J.H.:

Animal model estimation of additive and dominance variances in egg production traits of poultry. J. Anim. Sci. 71 (1993), 57-65

WEI, M.; VAN der STEEN, H.A.M.; VAN der WEF, J.H.J.; BRASCAMP, E.W.:

Relationship between purebred and crossbred parameters. I. Variances and covariances under the onelocus model. J. Anim. Breed. Genet. 108 (1991a), 253-261

WEI, M.; VAN der WERF, J.H.J.; BRASCAMP, E.W.:

Relationship between purebred and crossbred parameters II. Genetic correlation between purebred and crossbred performance under the model with two loci. J. Anim. Breed. Genet. 108 (1991b), 262-269

Received: 2005-11-22

Accepted: 2006-02-21

Corresponding Author

Dr. NORBERT MIELENZ

Institut für Tierzucht und Tierhaltung mit Tierklinik

der Martin-Luther-Universität Halle-Wittenberg

Adam-Kuckhoff-Straße 35

06108 HALLE

GERMANY

E-mail: norbert.mielenz@landw.uni-halle.de 